\title{
Information Transmission Capacity and Robustness of Natural Resource Governance Networks in Brazil and Indonesia: A Comparative Analysis
}

\author{
Philipp Gorris ${ }^{1}$ \\ Institute of Geography, Osnabrück University, Lower Saxony, Germany \\ Marion Glaser \\ Social-Ecological Systems Analysis Working Group, Social Science Department, \\ Leibniz Centre for Tropical Marine Research, Bremen, Germany
}

\section{Abstract}

How do different approaches to collaborative natural resource governance impact the associated actor networks' potential for rapid information transmission, and their robustness when subject to sociopolitical change? This is studied in the context of two cases that represent different archetypal regional approaches to coral reef governance. The case in Brazil adopts a centrally coordinated, large-scale protected area governance approach, whereas a self-organized polycentric governance approach is evident in the Indonesian case. Extensive empirical data are analyzed based on social network analysis and an innovative approach for simulating the effects of sociopolitical change on networks. The results show that both governance approaches shaped networks with surprisingly similar information transmission capacity. The network formed by the self-organized polycentric governance approach is found to be more robust than the centrally coordinated network. Mechanisms that contribute to shape the network pattern in the study areas are discussed.

Keywords: collaborative governance, comanagement, coral reef, polycentric governance, protected area, social network analysis.

\section{Introduction}

This research focuses on the information transmission capacity and robustness of actor networks that emerge from different approaches to collaborative governance of coastal and marine natural resources. Coastal and marine ecosystems are among the most productive ecosystems on earth and humans derive a wide variety of benefits from

1 Corresponding author: philipp.gorris@uni-osnabrueck.de. Philipp Gorris conducted this study at the Institute of Environmental Systems Research (IUSF), Osnabrück University. 
them (Cinner, 2014; Ferrol-Schulte et al., 2015). However, increasing anthropogenic pressures have led to extensive and sometimes irreversible damage of these ecosystems (Hughes et al., 2017). The human-nature relationships associated with these ecosystems are dynamic, place-specific, and may cause surprising repercussions across sectors and large territorial distances (Hughes et al., 2013). This renders governance highly challenging and the availability of information key for successfully resolving coastal and marine sustainability problems (Cinner et al., 2012).

Natural resource governance networks are widely recognized as playing an essential role in gathering and synthesizing knowledge (Alexander et al., 2016; Gerhardinger et al., 2018). Information and knowledge are not equally distributed in a social system, but certain actors possess information on a particular subject, while other actors hold more detailed information in another field of expertise (Wilson, 2002). Actors in the social system thus function as sources of different types of information due to their specific knowledge (Glaser, Radjawali, et al., 2010). For instance, some actors (e.g., fishers) may provide detailed information on changes to one resource (e.g., pelagic fish stocks), while other actors (e.g., dive tourism operators) may hold knowledge on changes to another resource (e.g., coral reefs) (Alexander et al., 2017; Galaz et al., 2016). Scholars consequently argue that integrating a wide variety of actors in governance networks is useful; for instance, for combining local and traditional knowledge with modern science-based knowledge to expand the overall knowledge base in management (Aswani \& Hamilton, 2004; Berkes, 2004) and to foster collective learning (Newig et al., 2010). In practice, such governance networks consist of different relational configurations between the actors with distinct (dis-)advantages for information transmission (Bodin, 2017).

This research centers on the question of how natural resource governance approaches impact the associated actor networks' potential for facilitating rapid information transmission between actors, and their robustness in terms of maintaining this function when subject to sociopolitical changes. This is studied based on a comparative case study approach in the context of coral reef governance in two cases: the "Coral Coast Environmental Protection Area (CC-EPA)" in the northeast of Brazil and the "Spermonde Archipelago" off the southern coast of Sulawesi in Indonesia. These cases were selected because they are very similar with regards to two important characteristics. First, the sustainability challenges surrounding the use of coral reef ecosystems are addressed through decentralized political systems in both countries (Wever et al., 2012). Second, regional collaborative approaches to environmental governance are in place with the purpose of bridging jurisdictional boundaries to address the problem of fit between ecological and governance processes in decentralized political systems (Jones, 2014; Young, 2006). These two characteristics are representative for many coastal marine natural resource governance efforts (Jones, 2014; Wever et al., 2012). In such contexts, integrated, regional, and collaborative governance approaches are initiated and implemented differently in practice. According to Jones (2014), two different archetypal 
approaches can be identified for this type of governance effort. First, governance may be initiated and implemented through a self-organized polycentric approach and, second, through an externally coordinated central government-led approach with procedural mechanisms for stakeholder participation. The cases selected for this research represent one case from each category, to improve understanding of the presumably differing potentials of the resultant governance networks with regard to their information transmission capacity and robustness.

Social network analysis (SNA) is used to examine the social structural configurations of the two governance networks for their information transmission capacity. For the robustness assessment, a consecutive targeted node removal procedure is used to simulate the impact of sociopolitical changes on the governance networks. Mechanisms that contribute to shape the observed network pattern in the study areas are discussed based on qualitative data.

The findings of this study fill at least two important gaps in the literature. First, research on the (dis-)advantages of distinct relational structures in environmental governance networks is constantly growing (Bodin, 2017; Groce et al., 2019; Kluger et al., 2020). Yet, whether these structures are shaped by different approaches to collaborative natural resource governance remains an open question. Moreover, second, while the interplay between information transmission capacity and network structure has received some attention in conceptual research (Bodin \& Crona, 2009; Newig et al., 2010), empirical social network studies on information transmission in environmental governance are scare and empirical studies on robustness of environmental governance networks absent. In addition, the findings of this study contribute to understanding of the (dis-)advantages of adopting one or another type of governance approach for resolving natural resource problems.

The article proceeds as follows: Section 2 combines literature from social network studies with research on governing natural resources to formulate hypotheses on how the two governance approaches impact their associated actor networks' capacity for transmitting information and their robustness. Section 3 describes the methods for data collection and analyses before the results are presented and discussed in Section 4. The article concludes with Section 5, which highlights key insights of the study.

\section{Governance networks, information transmission, and robustness}

Social network scholarship highlights that a network's potential for the transmission of information and knowledge is tightly linked to reachability (Bodin et al., 2006). A high degree of reachability in a network is achieved when all actors are connected to the network; that is, the network displays a low degree of fragmentation. This ensures that all actors in the network can be reached via direct contact by at 
least one other actor. Another important determinant of reachability is whether the network is patterned in a way that most actors can directly contact the majority of other actors, or at least indirectly reach each other via only a few steps between other actors in the network (Wasserman \& Faust, 1994). Actors can thus gain fast access to information from all others in the most direct way (Abrahamson $\&$ Rosenkopf, 1997).

Robustness generally refers to the capacity of a system to maintain key properties and functions either when subject to external perturbations or internal stresses (Anderies et al., 2004). In this article, the term robustness specifically refers to the network's capacity to maintain its information and knowledge transmission capacity in the face of sociopolitical change. Sociopolitical change alters the composition of a governance network. This occurs, for instance, when important government agencies experience cutbacks in terms of personnel allocated to contribute to the governance process, or when funding for projects or nongovernmental organizations (NGOs) breaks away (thereby reducing or erasing the role that respective actors can play in the governance process). Another case of even larger scale changes in governance networks might occur when a subject to be governed (such as marine conservation) loses priority with shifts in the general political agenda (e.g., following elections). Then, multiple actors may withdraw from an ongoing governance process and turn their attention to another subject. This has severe consequences for the capacity of the entire governance network to resolve sustainability problems (Folke et al., 2005).

For investigating the information transmission capacity and the robustness of governance networks, this study focuses on a large-scale marine protected area (MPA) managed by a central government authority in Brazil and a self-organized polycentric regional governance approach in Indonesia. The Brazilian "Coral Coast Environmental Protection Area" (CC-EPA), established in 1997, is located in the states of Pernambuco and Alagoas. A large-scale MPA approach was adopted to ensure the conservation of coral reefs, beaches, mangroves, and manatees, and to maintain the culture of coastal communities by regulating tourism and fishing (ICMBio, ${ }^{2}$ 2013). Covering a total area of 413.563 ha, the CC-EPA extends from 33 meters above the average high tide to 18 nautical miles off the coastline, and includes $135 \mathrm{~km}$ of coastline (ICMBio, 2013). The CC-EPA is under federal responsibility and managed by the national government authority ICMBio. The "consultative council of the CC-EPA" (the locally used acronym of the council is CONAPACC, for "Conselho Consultivo da Área de Proteção Ambiental Costa dos Corais") is composed of governmental and nongovernmental actors and complements management through a regional forum for stakeholder involvement. Any rules and regulations are formulated through an interactive process between

2 Instituto Chico Mendes de Conservaçãcao da Biodiversidade (Chico Mendes Institute for Biodiversity Conservation). 
the MPA managers and the CONAPACC (Glaser et al., 2018). Such participatory large-scale MPA approaches led by national government authorities are widely used in Brazil and are very common in many countries all over the world (Jones, 2014).

The Indonesian Spermonde Archipelago is located off the southern coast of Sulawesi and comprises about 80-100 small islands. The Spermonde Archipelago territory is, just as in the Brazilian case, subdivided into the two administrative units Makassar district and Pangkajene Kepulauan district (Pangkep), each with responsibility to manage the islands and the sea within their jurisdictional territory. Unlike in the Brazilian case, with its central government-led participatory MPA approach, a range of governmental and nongovernmental actors from multiple levels in the state hierarchy are involved in collaborative strategic marine planning, implementation of conservation programs, monitoring, and enforcement (Glaeser et al., 2017). Whereas an overarching institutional framework at the regional level (e.g., a large-scale MPA) is de facto absent, a number of small community-based notake areas are declared (Glaser, Baitoningsih, et al., 2010). Moreover, independent of these small MPAs and other higher level marine management measures, effective area-based rules surrounding a number of islands have emerged at the community level all over the archipelago (Glaser, Baitoningsih, et al., 2010). These include, for instance, the prohibition of destructive activities (e.g., bomb and poison fishing) by informal agreements, which are enforced locally (Gorris, 2016). Such dispersal of authority across the political system in combination with high degrees of overlap of responsibilities establishes a polycentric governance system that strongly relies on self-organized coordination and collaboration among the relevant actors (Andersson \& Ostrom, 2008; Carlisle \& Gruby, 2019; Gorris et al., 2019).

Social network theory suggests that the existence of central coordinators increases information transmission in governance networks (Bodin \& Crona, 2009). In the Brazilian case, MPA managers actively coordinate coral reef governance and steer the network. Furthermore, the CONAPACC offers a platform to integrate actors from the relevant sectors and the different affected communities in the Brazilian governance network. Such active coordination in combination with the existence of boundary-spanning multi-actor platforms are viewed as particularly important for enhancing the information transmission capacity of governance networks (Berdej \& Armitage, 2016; Hamilton et al., 2020). As for the Indonesian case, conversely, previous research suggests that dispersed responsibility for environmental governance across the political hierarchy and the lack of a regional overarching coordinating framework often result in fragmented regional governance (Jones, 2014; Wever et al., 2012; Young, 2006). Such fragmented regional governance most likely leads to deficits in information transmission among the relevant actors (Bodin \& Crona, 2009). Consequently, we deduce the following hypothesis: 
Hypothesis 1: The centrally coordinated governance approach in the Brazilian case shapes an actor network with a higher information transmission capacity than the polycentric governance approach in the Indonesian case.

Information transmission capacity is measured based on the networks' reachability. A lower reachability of the governance network in the Indonesian case than in the Brazilian case provides support for hypothesis 1 .

With regards to the robustness of a governance network, in terms of maintaining its information transmission capacity when subject to sociopolitical change, network theory suggests that if only one or few actors are responsible for connecting large numbers of actors, the disappearance of these key actors causes numerous actors to be connected in less direct ways, or causes a full disconnection of parts of the network (Borgatti, 2003). This indicates vulnerability of the network to the removal or failure of the key actors (Frank et al., 2007). In the Brazilian case, the MPA managers assume an outstanding key role in the governance system through their coordinating and steering function. Polycentric approaches with overlapping authority and responsibilities, as in the Indonesian case, rather create redundancy of actor roles (Carlisle \& Gruby, 2019). This redundancy is a critical element to enhance robustness in the face of sociopolitical change (Janssen et al., 2006). Consequently, we assume the following for our cases:

Hypothesis 2: The polycentric governance approach in the Indonesian case shapes a more robust actor network than the centrally coordinated approach in the Brazilian case.

The networks' robustness is tested by simulating the effects of sociopolitical change on the governance networks' reachability through a targeted elimination of actors from the network. For supporting hypothesis 2, we expect that the withdrawal of actors from the governance networks decreases the degree of reachability in the Brazilian case faster than in the Indonesian case.

\section{Methods}

\subsection{Data collection}

The hypotheses are tested using extensive empirical data collected from the two study areas. A list of institutional actors (a so-called stakeholder roster in SNA terminology) with functional roles in marine governance was developed based on reviewing official documents (e.g., meeting protocols) and in-depth interviews with district administration personnel and university scholars. The stakeholder roster was left open so that respondents could add links as needed. Subsequently, face-toface interviews with a structured survey instrument were conducted to collect data 
about interaction among marine governance actors in the Indonesian Spermonde Archipelago and the Brazilian CC-EPA. The use of a stakeholder roster was chosen rather than snowball sampling to ensure that possibly disconnected components of the network could be detected. 105 interviews were conducted in Indonesia with governmental and nongovernmental actors $(\mathrm{n}=129)$ from September 2012 to March 2013 (ca. 80 percent response rate). Eighty-nine interviews were conducted with actors $(\mathrm{n}=110)$ in the Brazilian study region from July to December 2013 (ca. 80 percent response rate).

While all actors listed on the stakeholder roster were approached to take part in the study, some actors did not want to be interviewed. Yet, according to the key informants who helped to develop the stakeholder roster, the missing actors did not assume important roles in the networks (which, for some actors, may also be the reason why they refused to take part in the study). We thus decided to include the not-interviewed actors in our analysis and use a symmetric non-directional relational data set. We generally acknowledge that missing data reduce the validity of the results, because network analysis is sensitive to missing data (Groce et al., 2019). However, we believe that, for this study, including the "missings" enhances the validity of the results more than excluding them (and their links).

The relational data were complemented by semi-structured key informant interviews (KIIs, $n=18$ in Brazil, $n=21$ in Indonesia) to allow for a more in-depth understanding of the roles and responsibilities of the different actors in marine governance and of the impact of governance design instruments (i.e., regional stakeholder meetings) on the network structure, and to contextually ground the findings of the SNA. These interviews were held with government officials, representatives of NGOs, and university scholars. KIIs were recorded and transcribed, but no systematic content analysis was carried out. Publicly available documents including project descriptions, management plans, legal documents, and written agreements were reviewed to validate qualitative data.

\subsection{Data analysis}

Analysis of the relational data was carried out in two steps to investigate differences in the actor networks resulting from the two different approaches to governance. First, reachability was assessed to examine the networks' information transmission capacity. Second, we conducted a network robustness assessment to test whether this information transmission capacity can be maintained over time when the network is subject to sociopolitical change. UCINET (Borgatti et al., 2002) and Gephi (Bastian et al., 2009) software was used for analysis of the relational data and the latter also for visualization of the networks. 


\subsubsection{Assessment of reachability in the networks}

Following the suggestion by Bodin et al. (2006), reachability at the network level is assessed by analyzing the fragmentation and diameter of the networks. Fragmentation is measured through component analysis. A component is a part of a larger network that is disconnected from the rest of the network (Wasserman $\&$ Faust, 1994). If a network consists of more than one component, it is considered fragmented (Bodin et al., 2006). The degree of fragmentation is quantified by the number of components; that is, the higher the number of components in a network, the higher is its fragmentation, because the actors in one component cannot directly communicate with the actors in another component. This reduces reachability in the network. The diameter measures the actors' ability to directly communicate with all other actors in the network. The diameter is defined as the average length of the shortest paths between any two nodes in the network (Wasserman \& Faust, 1994). The smaller the diameter is, the better the ability of all actors in the network to communicate with each other.

In addition to these two reachability measurements suggested by Bodin et al. (2006), we include the network measure density in our reachability assessment, because we consider the connectedness of networks to also be an important enhancing factor of reachability that improves information transmission in networks. Density analyzes to what extent all actors in the network are tied to one another. Density is calculated as the proportion of links realized relative to the maximum number of links possible in the network (Wasserman \& Faust, 1994). A density score of 1 indicates that all actors of the network are directly linked with each other (i.e., the network is fully connected). A score of 0 indicates that no single actor has a link to any other actor in the network (i.e., the network is fully disconnected). Although the two cases have a relatively similar number of actors in their networks, note that smaller networks tend to have higher densities (Wasserman \& Faust, 1994).

\subsubsection{Assessment of network robustness}

The robustness of the networks is studied by examining the governance networks' ability to maintain their information transmission capacity based on the reachability of the network when subject to sociopolitical change. The withdrawal of any actor from the governance network removes that actor's links that contribute to the reachability of the network. For simulating such changes in the two cases' governance networks we used a consecutive targeted node removal procedure (for details see Albert et al., 2000). In each step, the actor with the highest closeness centrality was removed until no link was left in the network. The node-level measure closeness centrality analyzes an actor's reachability in a network by calculating the average geodesic distance between the actors; that is, the average number of steps needed for any actor (ego) to reach all other actors (alters) in the network (Freeman, 1979). 
Actors with high closeness centrality scores function as important hubs for information transmission, because they can reach all other actors in the network through only a few steps. Closeness centrality was chosen (rather than degree centrality), because it indicates actors with high importance for maintaining the network's information transmission capacity considering the entire network, rather than only an actor's direct links (i.e., actors with high degree centrality) (Freeman, 1979).

Following Anderies et al. (2004), we consider the robustness of a network to be high if the network is able to (at least partly) maintain its key properties and functions in the face of (simulated) change. Two measures were used to assess the networks' robustness. First, we measured the number of nodes to be removed until decay (i.e., no link in the entire network was left). The percentage of nodes to be removed from the network until decay indicates the speed with which the network decays (relative to the size of the network); that is, the lower the percentage of nodes to be removed until decay, the faster the network decays and, consequently, the lower is its robustness. Second, the development of the networks' reachability during the node removal process was measured. Therefore, the network's density and fragmentation (i.e., number of components) are calculated at each step in the consecutive node removal process until the network is fully decayed. We compared the slopes produced by the values for density and fragmentation between the two governance networks to assess their robustness; that is, the faster the density decreased and the fragmentation increased, the less robust we consider the network to be with regards to maintaining their information transmission capacity. For determining the steepness of the slopes, the following geographical slope estimation was used.

$$
m=\frac{y_{2}-y_{1}}{x_{2}-x_{1}}
$$

$y_{1}$ represents the first point and $y_{2}$ the last point on the y-axis (same for $x_{1}$ and $x_{2}$ ). $m$ denotes the absolute value of the slope. The higher the value for positive values (and the lower for negative values), the steeper the slope. Separate slope estimations were calculated for (A) the density values and (B) the number of components (indicating fragmentation) obtained after each step during the node removal procedure in each case.

Note that the networks' diameter (i.e., the third characteristic of reachability used in this study), for which only the largest component is measured, could not be included in the network robustness assessment. This is because the node removal process quickly leads to fragmented networks and the measure becomes highly biased with increasing network fragmentation. 


\section{Results and discussion}

\subsection{The governance networks' information transmission capacity}

Figure 1 shows a visualization of the networks. Table 1 shows the results of the networks' reachability analysis. Interestingly, both regional governance approaches trigger actor networks with the same density. The component analysis shows for the Indonesian governance network that any actor in the network can be reached via direct or indirect social interactions and the network is not fragmented. For the Brazilian network, the results show two components in the network. Yet, similar to the Indonesian network, the Brazilian network consists of one large component, which represents the overall governance network, and one only very small component (see Figure 1). The small component consists of only four actors who are connected to each other, but not to the overall network. Hence, the Brazilian networks also has a very low degree of fragmentation. The diameter in the Brazilian network is slightly higher than in the Indonesian network; that is, one more step is needed on average in the Brazilian network to reach all other actors from any given node than in the Indonesian network. In conclusion, while the reachability in the actor networks is surprisingly similar, the higher number of components and the higher diameter in Brazilian case show a slightly lower overall reachability compared with the Indonesian case.

Table 1. Characteristics of the governance networks.

\begin{tabular}{|c|c|c|c|c|c|c|}
\hline Case & $\begin{array}{l}\text { Governance } \\
\text { approach }\end{array}$ & $\begin{array}{l}\text { No. of } \\
\text { actors }\end{array}$ & $\begin{array}{l}\text { No. of } \\
\text { links }\end{array}$ & Density & Diameter & Components \\
\hline $\begin{array}{l}\text { Coral Coast } \\
\text { Environ. } \\
\text { Protection Area, } \\
\text { Brazil } \\
\end{array}$ & $\begin{array}{l}\text { Large-scale } \\
\text { marine protected } \\
\text { area governance } \\
\text { approach }\end{array}$ & 110 & 478 & 0.07 & 6 & 2 \\
\hline $\begin{array}{l}\text { Spermonde } \\
\text { Archipelago, } \\
\text { Indonesia }\end{array}$ & $\begin{array}{l}\text { Self-organized } \\
\text { polycentric } \\
\text { governance } \\
\text { approach }\end{array}$ & 129 & 655 & 0.07 & 5 & 1 \\
\hline
\end{tabular}

Note: See Section 3.2 for details on how density, diameter, and number of components are calculated. Source: Authors' summary.

These results thus do not support hypothesis 1, that the governance approach in the Brazilian case shapes an actor network with higher information transmission capacity than the one in the Indonesian case. Instead, the results suggest that the polycentric approach shaped a network with a slightly higher information transmission capacity than the centrally coordinated governance approach. This result is surprising given that scholarship emphasizes the importance of coordinators and of boundaryspanning multi-actor platforms, as implemented in the Brazilian case, for enhancing the information transmission capacity of governance networks (Berdej \& Armitage, 2016; Bodin \& Crona, 2009; Hamilton et al., 2020). 


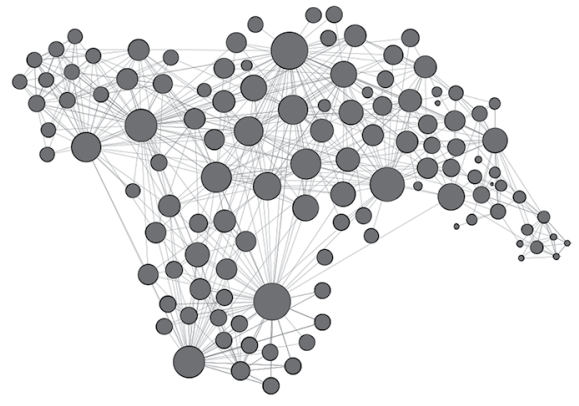

Indonesia

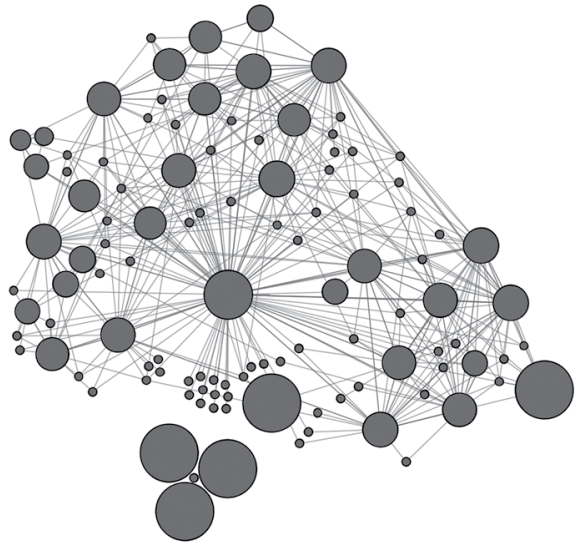

Brazil

Figure 1. Visual representation of the governance networks. The node size is scaled to the actors' "closeness centrality" scores (the larger the nodes, the higher the score).

Source: Authors' representation.

Information from the Brazilian KIIs helps to explain these results. Interviewees confirmed that the MPA managers take a strong steering role in governance. Furthermore, interviewees stated that the regional forum, the CONAPACC, led to the formation of what may be called a "regional conservation clique." More specifically, the CONAPACC is a membership organization joined by a (limited) number of governmental and nongovernmental actors and, as both the network analysis and qualitative data show, this seems to have facilitated the formation of a strongly connected core group in the network. Actors outside this clique, who are mostly local actors and with limited organizational capacity (e.g., small-scale fisher associations, small tourism business associations, local NGOs), do not participate in the regional forum and are only weakly connected. A core-periphery network structure with high inequality in the distribution of links (i.e., high variance in the closeness centrality scores, see Figure 1) is thus formed. In this overall structure, the network's core involving the MPA managers and the conservation clique is tightly connected whereas the periphery is only sparsely connected. This sparsely connected periphery reduces overall reachability in the governance network and inhibits the information transmission capacity of the network as a whole.

In contrast, the expected fragmentation of the Indonesian governance network resulting from the dispersal of responsibilities across the political system is not reflected in the results. According to information from Indonesian KIIs, when relevant issues arise, actors from the involved communities and from the different levels in the Indonesian political system (villages, districts, and the province) include the topic on the agenda of other more general forums or organize ad hoc meetings. Most importantly, the Indonesian informants emphasized that the actors exchange 
information through informal interaction. A decentralized, more integrative network with a low inequality in link distribution was thus formed, rather than a core-periphery network as in the Brazilian case. This self-organized polycentric governance approach in the Indonesian case thus shaped an actor network with a slightly higher information transmission capacity than the centrally coordinated approach in the Brazilian case.

\subsection{The governance networks' robustness}

How well is the information transmission capacity of the governance networks maintained when subject to sociopolitical changes? The results of the robustness assessment are presented in Table 2 and Figure 2. The results show that, compared with the Indonesian case, in the Brazilian case a lower percentage of nodes had to be removed until the network was completely disconnected (Table 2). Moreover, the slopes produced by the values for density and the number of components during the simulation process show that the Brazilian network's connectivity decreased (Figure 2A, Table 2) and fragmentation increased faster than in the Indonesian network (Figure 2B, Table 2).

Table 2. Results of the network robustness assessment.

\begin{tabular}{|l|c|c|}
\hline Measure & Indonesia & Brazil \\
\hline Steps to decay (0 edges left) & 54 & 32 \\
\hline Percent of nodes removed until decay (0 edges left) & $42 \%$ & $29 \%$ \\
\hline Network density: steepness of slope & -0.00132 & -0.00219 \\
\hline Fragmentation: steepness of slope & 1.396 & 2.375 \\
\hline
\end{tabular}

Source: Authors' summary.
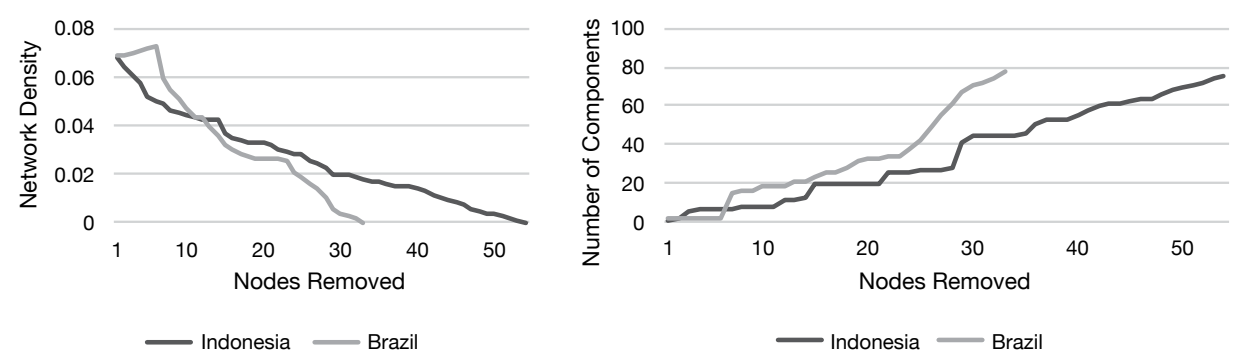

Figure 2. (A) Development of networks' density and (B) degree of fragmentation, during the targeted node removal process.

Source: Authors' representation. 
These results support our hypothesis 2 that the Indonesian governance network is more robust than the Brazilian network. As expected, the coordinated governance approach in Brazil resulted in a lack of redundancy of actors with structural key roles in the network. This renders the governance network in the Brazilian case structurally vulnerable to the loss of critically important actor roles (Borgatti, 2003). The Brazilian governance network consequently fragmented more rapidly than the Indonesian network, as the MPA managers with key roles and, subsequently, the actors from the "regional conservation clique" were removed very early in the simulation.

The results of the simulation are supported by the KIIs. A number of Brazilian informants emphasized that the MPA managers do their job very well and that they are critical to ensure effective coral reef governance, especially by means of their function as knowledge hubs in the network. This key role, however, has led to a situation in which the overall success of the MPA highly depends on the capacity of the MPA managers. Moreover, Brazilian KIIs stated that the "regional conservation clique" plays a central role for the information transmission in the network. Hence, while previous research suggests that leadership is an important driver of resource governance effectiveness (Gutiérrez et al., 2011), the results of this study emphasize that the reliance on the capacity of leaders and a small conservation elite may be problematic, because it increases vulnerability to sociopolitical changes.

In line with the arguments by polycentricity scholars (Carlisle \& Gruby, 2019; McGinnis, 2000), the Indonesian network shaped by the self-organized polycentric governance approach, in contrast, is found to be more robust than the coordinated Brazilian one. The main reason is that the polycentric approach formed a network with much lower inequality in reachability among the governance actors than the Brazilian approach. Both the results of the network analysis and the Indonesian KIIs suggest that the actors in the Indonesian case form several sub-clusters in different governance units nested across the political system (i.e., villages, districts, province). These sub-clusters are also connected with each other via information exchange. A high degree of robustness in terms of maintaining the network's structural capacity to transmit information when subject to sociopolitical changes could thus be achieved in the Indonesian governance network.

Table 3. Summary of the results.

\begin{tabular}{|l|l|l|l|l|}
\hline Case & Location & Governance approach & $\begin{array}{l}\text { Information } \\
\text { transmission } \\
\text { capacity }\end{array}$ & Robustness \\
\hline $\begin{array}{l}\text { Coral Coast } \\
\text { Environmental } \\
\text { Protection Area }\end{array}$ & $\begin{array}{l}\text { Northeastern } \\
\text { Brazil }\end{array}$ & $\begin{array}{l}\text { Centrally coordinated } \\
\text { large-scale MPA } \\
\text { governance approach }\end{array}$ & $\begin{array}{l}\text { Very similar } \\
\text { (slightly lower) }\end{array}$ & Lower \\
\hline $\begin{array}{l}\text { Spermonde } \\
\text { Archipelago }\end{array}$ & $\begin{array}{l}\text { Central } \\
\text { Indonesia }\end{array}$ & $\begin{array}{l}\text { Self-organized polycentric } \\
\text { governance approach }\end{array}$ & $\begin{array}{l}\text { Very similar } \\
\text { (slightly higher) }\end{array}$ & Higher \\
\hline
\end{tabular}

Source: Authors' summary. 


\subsection{Limitations of the study}

There are limitations to this study. Importantly, the results are not generalizable, because this is a two-case comparative study. The quantitative network analysis as used in this study can only shed light on the potential of a given relational structure among actors in a governance network in terms of information transmission, but neither deliver insights on the actual content transmitted through the network, nor on the quality or usefulness of transmitted information for the actors. Finally, the simulation of sociopolitical change through consecutive node removal does not take into account that the loss of actors from the governance network might, in practice, lead to reactive link formation to cope with the change.

\section{Conclusion}

Based on two archetypal cases, this comparative research examined how adopting different approaches to collaborative regional natural resource governance impacts the associated actor networks' capacity for facilitating information transmission and their robustness in terms of maintaining this function when subject to sociopolitical changes. A centrally coordinated regional MPA governance approach is adopted in the Brazilian case, whereas a more self-organized polycentric governance approach is evident in the Indonesian case. Social network analysis and an innovative simulation approach was used to analyze extensive empirical data.

The findings contribute interesting insights on the interplay between governance characteristics, the resultant actor network structure, and their specific (dis-) advantages. The different governance approaches shaped actor networks with distinct relational structures. Both networks entail a similar capacity for information transmission, while the self-organized polycentric governance network is more robust when subject to sociopolitical change. Consequently, this study contributes further evidence that self-organized polycentric approaches are a viable alternative for natural resource governance (Carlisle \& Gruby, 2019; McGinnis, 2000). How natural resource governance networks can be better supported to enhance their robustness in times of sociopolitical change remains an important question for future research.

\section{Acknowledgments}

We thank M. Verweij, A. Schlüter, and the anonymous reviewers for their constructive comments and suggestions on earlier versions of the manuscript. Financial support was received from the SPICE III Project (grant number 03F0643A) funded by the German Ministry for Research and Education (BMBF) 
and the Leibniz Centre for Tropical Marine Research (ZMT) in Bremen, Germany. PG acknowledges financial support from the Alexander-von-Humboldt $(\mathrm{AvH})$ professorship for Environmental Economics of the Osnabrück University (UOS).

\section{References}

Abrahamson, E., \& Rosenkopf, L. (1997). Social network effects on the extent of innovation diffusion: A computer simulation. Organization Science, 8(3), 289-309. doi.org/10.1287/ orsc.8.3.289

Albert, R., Jeong, H., \& Barabási, A.-L. (2000). Error and attack tolerance of complex networks. Nature, 406(6794), 378-382. doi.org/10.1038/35019019

Alexander, S. M., Andrachuk, M., \& Armitage, D. (2016). Navigating governance networks for community-based conservation. Frontiers in Ecology and the Environment, 14(3), 155-164. doi.org/10.1002/fee.1251

Alexander, S. M., Armitage, D., Carrington, P. J., \& Bodin, Ö. (2017). Examining horizontal and vertical social ties to achieve social-ecological fit in an emerging marine reserve network. Aquatic Conservation: Marine and Freshwater Ecosystems, 27(6), 1209-1223. doi.org/10.1002/aqc. 2775

Anderies, J. M., Janssen, M. A., \& Ostrom, E. (2004). A framework to analyze the robustness of social-ecological systems from an institutional perspective. Ecology and Society, 9(1), Article 18. doi.org/10.5751/es-00610-090118

Andersson, K., \& Ostrom, E. (2008). Analyzing decentralized resource regimes from a polycentric perspective. Policy Sciences, 41(1), 71-93. doi.org/10.1007/s11077-0079055-6

Aswani, S., \& Hamilton, R. J. (2004). Integrating indigenous ecological knowledge and customary sea tenure with marine and social science for conservation of bumphead parrotfish (Bolbometopon muricatum) in the Roviana Lagoon, Solomon Islands. Environmental Conservation, 31(1), 69-83. doi.org/10.1017/s037689290400116x

Bastian, M., Heymann, S., \& Jacomy, M. (2009). Gephi: An open source software for exploring and manipulating networks. Proceedings of the International AAAI Conference on Weblogs and Social Media, 3(1). ojs.aaai.org/index.php/ICWSM/article/view/13937

Berdej, S. M., \& Armitage, D. R. (2016). Bridging organizations drive effective governance outcomes for conservation of Indonesia's marine systems. PLoS ONE, 11(1), Article e0147142. doi.org/10.1371/journal.pone. 0147142

Berkes, F. (2004). Rethinking community-based conservation. Conservation Biology, 18(3), 621-630. doi.org/10.1111/j.1523-1739.2004.00077.x

Bodin, Ö. (2017). Collaborative environmental governance: Achieving collective action in social-ecological systems. Science, 357(6352). doi.org/10.1126/science.aan1114 
Bodin, Ö., \& Crona, B. I. (2009). The role of social networks in natural resource governance: What relational patterns make a difference? Global Environmental Change, 19(3), 366-374. doi.org/10.1016/j.gloenvcha.2009.05.002

Bodin, Ö., Crona, B., \& Ernstson, H. (2006). Social networks in natural resource management: What is there to learn from a structural perspective? Ecology and Society, 11(2), Response 2. doi.org/10.5751/es-01808-1102r02

Borgatti, S. P. (2003). The key player problem. In R. Breiger, K. Carley, \& P. Pattison (Eds.), Dynamic social network modeling and analysis: Workshop summary and papers (pp. 241-252). National Academies Press. doi.org/10.17226/10735

Borgatti, S. P., Everett, M. G., \& Freeman, L. C. (2002). UCINET for Windows (Version 6.580) [Computer software]. Analytic Technologies. sites.google.com/site/ucinetsoftware/home

Carlisle, K., \& Gruby, R. L. (2019). Polycentric systems of governance: A theoretical model for the commons. Policy Studies Journal, 47(4), 927-952. doi.org/10.1111/psj.12212

Cinner, J. (2014). Coral reef livelihoods. Current Opinion in Environmental Sustainability, 7 , 65-71. doi.org/10.1016/j.cosust.2013.11.025

Cinner, J. E., McClanahan, T. R., MacNeil, M. A., Nicholas, A. J., Daw, T. M., Mukminin, A., ... Kuange, J. (2012). Comanagement of coral reef social-ecological systems. Proceedings of the National Academy of Sciences, 109(14), 5219-5222. doi.org/10.1073/ pnas.1121215109

Ferrol-Schulte, D., Gorris, P., Baitoningsih, W., Adhuri, D. S., \& Ferse, S. C. A. (2015). Coastal livelihood vulnerability to marine resource degradation: A review of the Indonesian national coastal and marine policy framework. Marine Policy, 52, 163-171. doi.org/10.1016/j.marpol.2014.09.026

Folke, C., Hahn, T., Olsson, P., \& Norberg, J. (2005). Adaptive governance of social-ecological systems. Annual Review of Environment and Resources, 30(1), 441-473. doi.org/10.1146/ annurev.energy.30.050504.144511

Frank, K. A., Mueller, K., Krause, A., Taylor, W., \& Leonard, N. (2007). The intersection of global trade, social networks, and fisheries. In W. W. Taylor, M. G. Schechter, \& L. G. Wolfson (Eds.), Globalization: Effects on fisheries resources (pp. 385-423). Cambridge University Press. doi.org/10.1017/cbo9780511542183.020

Freeman, L. C. (1979). Centrality in social networks conceptual clarification. Social Networks, 1, 215-239. doi.org/10.1016/0378-8733(78)90021-7

Galaz, V., Österblom, H., Bodin, Ö., \& Crona, B. (2016). Global networks and global change-induced tipping points. International Environmental Agreements: Politics, Law and Economics, 16, 189-221. doi.org/10.1007/s10784-014-9253-6 
Gerhardinger, L. C., Gorris, P., Gonçalves, L. R., Herbst, D. F., Vila-Nova, D. A., De Carvalho, F. G., ... Glavovic, B. (2018). Healing Brazil's Blue Amazon: The role of knowledge networks in nurturing cross-scale transformations at the frontlines of ocean sustainability. Frontiers in Marine Science-Marine Affairs and Policy, 4, Article 395. doi.org/10.3389/ fmars.2017.00395

Glaeser, B., Ferse, S. C. A., \& Gorris, P. (2017). Fisheries in Indonesia between livelihoods and environmental degradation: Coping strategies in the Spermonde Archipelago, Sulawesi. In P. Guillotreau, A. Bundy, \& R. I. Perry (Eds.), Global change in marine systems: Integrating natural, social and governing responses (pp. 67-82). Routledge. doi.org/ $10.4324 / 9781315163765-5$

Glaser, M., Baitoningsih, W., Ferse, S. C. A., Neil, M., \& Deswandi, R. (2010). Whose sustainability? Top-down participation and emergent rules in marine protected area management in Indonesia. Marine Policy, 34(6), 1215-1225. doi.org/10.1016/j.marpol. 2010.04.006

Glaser, M., Gorris, P., Ferreira, B. P., \& Breckwoldt, A. (2018). Analysing ecosystem user perceptions of the governance interactions surrounding a Brazilian near shore coral reef. Sustainability, 10(5), 1464. doi.org/10.3390/su10051464

Glaser, M., Radjawali, I., Ferse, S., \& Glaeser, B. (2010). "Nested” participation in hierarchical societies? Lessons for social-ecological research and management. International Journal of Society Systems Science, 2(4), 390-414. doi.org/10.1504/ijsss.2010.035571

Gorris, P. (2016). Deconstructing the reality of community-based management of marine resources in a small island context in Indonesia. Frontiers in Marine Science, 3, Article 120. doi.org/10.3389/fmars.2016.00120

Gorris, P., Glaser, M., Idrus, R., \& Yusuf, A. (2019). The role of social structure for governing natural resources in decentralized political systems: Insights from governing a fishery in Indonesia. Public Administration, 97(3), 654-670. doi.org/10.1111/padm.12586

Groce, J. E., Farrelly, M. A., Jorgensen, B. S., \& Cook, C. N. (2019). Using social-network research to improve outcomes in natural resource management. Conservation Biology, 33(1), 53-65. doi.org/10.1111/cobi.13127

Gutiérrez, N. L., Hilborn, R., \& Defeo, O. (2011). Leadership, social capital and incentives promote successful fisheries. Nature, 470(7334), 386-389. doi.org/10.1038/ nature09689

Hamilton, M., Hileman, J., \& Bodin, Ö. (2020). Evaluating heterogeneous brokerage: New conceptual and methodological approaches and their application to multi-level environmental governance networks. Social Networks, 61, 1-10. doi.org/10.1016/j.socnet. 2019.08.002

Hughes, T. P., Barnes, M. L., Bellwood, D. R., Cinner, J. E., Cumming, G. S., Jackson, J. B. C., ... Scheffer, M. (2017). Coral reefs in the Anthropocene. Nature, 546(7656), 82-90. doi.org/10.1038/nature22901 
Hughes, T. P., Huang, H. U. I., \& Young, M. A. L. (2013). The wicked problem of China's disappearing coral reefs. Conservation Biology, 27(2), 261-269. doi.org/10.1111/j.15231739.2012.01957.x

ICMBio. (2013). Plano de Manejo da Área de Proteção Ambiental Costa dos Corais (Management plan for the Costa Dos Corais environmental protection area). Instituto Chico Mendes de Conservação da Biodiversidade (Chico Mendes Institute for Biodiversity Conservation). icmbio.gov.br/apacostadoscorais/images/stories/plano_de_manejo/PM_APACC_2013_ JANEIRO.pdf

Janssen, M. A., Bodin, Ö., Anderies, J. M., Elmqvist, T., Ernstson, H., Mcallister, R. R. J., Olsson, P., \& Ryan, P. (2006). Toward a network perspective of the study of resilience in social-ecological systems. Ecology and Society, 11(1), Article 15. doi.org/10.5751/es$01462-110115$

Jones, P. J. S. (2014). Governing marine protected areas: Resilience through diversity. Routledge.

Kluger, L., Gorris, P., Kochalski, S., Müller, M., \& Romagnoni, G. (2020). Studying humannature relationships through a network lens: A systematic review. People and Nature, 2, 1100-1116. doi.org/10.1002/pan3.10136

McGinnis, M. D. (2000). Polycentric games and institutions: Readings from the workshop in political theory and policy analysis. University of Michigan Press. doi.org/10.3998/ mpub. 10728

Newig, J., Günther, D., \& Pahl-Wostl, C. (2010). Synapses in the network: Learning in governance networks in the context of environmental management. Ecology and Society, 15(4), Article 24. doi.org/10.5751/es-03713-150424

Wasserman, S., \& Faust, K. (1994). Social network analysis (5th ed.). Cambridge University Press. doi.org/10.1017/CBO9780511815478

Wever, L., Glaser, M., Gorris, P., \& Ferrol-Schulte, D. (2012). Decentralization and participation in integrated coastal management: Policy lessons from Brazil and Indonesia. Ocean \& Coastal Management, 66, 63-72. doi.org/10.1016/j.ocecoaman.2012.05.001

Wilson, J. (2002). Scientific uncertainty, complex systems and the design of common-pool institutions. In E. Ostrom, T. Dietz, N. Dolsak, P. C. Stern, S. Stonich, \& E. U. Weber (Eds.), The drama of the commons (pp. 327-359). The National Academies Press. doi.org/ $10.17226 / 10287$

Young, O. (2006). Vertical interplay among scale-dependent environmental and resource regimes. Ecology and Society, 11(1), Article 27. doi.org/10.5751/es-01519-110127 
This text is taken from Human Ecology Review, Volume 26, Number 2, 2020, published by ANU Press, The Australian National University, Canberra, Australia. doi.org/10.22459/HER.26.02.2020.05 